\title{
Kualitas Pelayanan Aplikasi DANA Terhadap Kepuasan Konsumen
}

\section{Quality Of 'DANA'Application Services On Consumer Satisfaction}

\author{
Akbar Gunawan ${ }^{1 *}$, Nuraida Wahyuni ${ }^{2}$, Vidya Nur Sheka ${ }^{3}$ \\ 1,2,3 Jurusan Teknik Industri, Universitas Sultan Ageng Tirtayasa \\ Penulis Korespondensi: Akbar Gunawan, a68ar@untirta.ac.id
}

\begin{abstract}
Abstrak
DANA merupakan aplikasi yang banyak memberi kemudahan dalam bertransaksi secara digital di Indonesia Gaya hidup manusia mulai terjadi pergeseran secara signifikan, dimana segala sesuatu dituntut untuk dilakukan secara cepat, mudah, dan praktis. Salah satu wujud kepraktisan yang ada di tengah masyarahat adalah maraknya sistem online. Saat ini DANA merupakan pembayaran e-wallet yang masih tergolong sangat baru di masyarakat. Karena itu aplikasi DANA ini masih dalam tahap pengembangan sehingga penelitian ini perlu dilakukan untuk memberikan daya tarik bagi kaum milenial. Penelitian ini melakukan dua tahap, yaitu pendahuluan dan pengambilan data. Pendahuluan berupa survey untuk uji validitas dan reabilitas kuesioner, sedangkan pengambilan data dengan penyebaran kuesioner kepada masyarakat pengguna Aplikasi DANA. Analisa dilakukan dengan menggunakan metode CSI dan IPA. Sampel yang diambil pada penelitian ini sebanyak 150 orang, dan terdapat 22 atribut dengan menggunakan 5 dimensi. Nilai presentase CSI yang diperoleh pada penelitian ini sebesar 77.1 \% yang merasa puas terhadap kualitas pelayanan pada Aplikasi DANA. Hasil penelitian ini menemukan 3 dari 22 atribut yang perlu ditingkatkan, 6 atribut yang harus di pertahankan dalam kualitas pelayanan, 9 atribut yang masih seimbang antara kinerja dengan kepentingan konsumen, dan 4 atribut yang kinerja lebih tinggi dari kepentingan konsumen. Adapun cara melakukan perbaikannya yaitu dengan menambahkan admin yang cepat menangani keluhan yang dialami oleh pelanggan, sehingga keluhan pelanggan dapat teratasi.
\end{abstract}

Kata kunci: CSI, IPA, Kepuasan Pelanggan

\begin{abstract}
DANA is an application that provides convenience in digital transactions in Indonesia. Human lifestyle has begun to shift significantly, where everything is required to be done quickly, easily, and practically. One form of practicality that exists in the community is the rise of online systems. Currently, DANA is an e-wallet payment that is still relatively new in the community. Therefore, this DANA application is still in the development stage so this research needs to be done to attract millennials. This research was conducted in two stages, namely the preliminary stage and the data collection stage. The preliminary stage is in the form of a survey to test the validity and reliability of the questionnaire, while data collection is done by distributing questionnaires to the public using the DANA application. The analysis was carried out using the CSI and IPA methods. The sample used in this study was 150 respondents, and there were 22 attributes using 5 dimensions. The CSI percentage value obtained in this study was $77.1 \%$ who were satisfied with the quality of service in the DANA application. The results of this study found 3 of 22 attributes that need to be improved, 6 attributes that must be maintained in service quality, 9 attributes that are still balanced between performance and the interests of consumers, and 4 attributes whose performance is higher than the interests of consumers. The way to fix it is by adding an admin who quickly handles complaints experienced by customers, so that customer complaints can be resolved.
\end{abstract}

Keywords: CSI,Customer Satisfaction, IPA.

Informasi Artikel:

Diterima tanggal 15 November 2021; Disetujui tanggal 4 Desember 2021; Terbit online tanggal 30 Desember 2021 


\section{Pendahuluan}

Gaya hidup seseorang sudah mulai bergeser dan pergeseran mulai tumbuh signifikan dimana segala sesuatu dilakukan secara online. Karena itu, teknologi saat ini sangat berpengaruh dalam kehidupan masyarakat yang menginginkan pergerakan lebih instan dan fleksible. Pada abad saat ini kegunaan internet telah menjadi gaya hidup, sehingga memicu perkembangan teknologi yang lebih pesat. Masyarakat modern banyak menggunakan teknologi dalam pemenuhan kebutuhan sehari-hari. Adanya peningkatan penggunaan internet di tengah masyarakat juga memicu semakin tingginya penggunaan telepon pintar (smartphone). Teknologi digital yang semakin maju banyak memberikan kemudahan dalam melakukan segala aktivitas, khususnya untuk pembayaran saat bertransaksi menggunakan perangkat seluler.

Pergerakan pasar global sangat cepat sehingga memicu perubahan dalam bersaing yang semakin ketat dalam bidang usaha, khususnya produk barang atau jasa yang memanfaatkan teknologi. Setiap produsen penyedia barang maupun layanan jasa harus berpikir keras dan selalu melakukan inovasi untuk memperebutkan pangsa pasar. Nilai merupakan pertimbangan terbesar bagi konsumen dalam memilih produk barang atau jasa. Produk barang maupun layanan jasa yang memberikan nilai terbesar akan banyak diminati oleh pangsa pasar. Hal ini penting untuk dipahami oleh para produsen agar mampu menyediakan kualitas dagang yang tinggi dan layanan yang mampu memuaskan pelanggan. Produk yang berkualitas dan layanan jasa yang baik juga bukan menjadi jaminan bagi konsumen untuk bergantung pada produk barang atau jasa yang diberikan oleh perusahaan tertentu (Afifudin, 2017).

Kepuasan dapat diartikan sebagai keinginan seseorang telah membandingkan antara harapan dengan output yang diperoleh. Kepuasan pelanggan dapat dinilai menggunakan SERVQUAL yang merupakan suatu pengukuran kualitas layanan dan analisis penyebab terjadinya hal - hal terkait manajemen, konsumen yang berkeinginan lebih besar hingga pegawai suatu perusahaan. Presepsi pelanggan atas kualitas layanan diukur menggunakan SERVQUAL yang meliputi lima unsur yaitu penampilan fisik (tangible), kepastian, kehandalan, tanggapan, dan empati. Dalam rangka meningkatkan pangsa pasar dan mencapai competitive advantage, kepuasan pelanggan ialah sesuatu yang penting bagi perusahaan dalam persaingan (Fadhillah, 2012). Pelayanan dikatakan memenuhi kebutuhan dan harapan pelanggan ketika pelayanan tersebut dinilai memuaskan konsumen. Perusahaan harus memperhatikan pengukuran kepuasan pelanggan karena hal ini sangat penting agar dapat menyediakan layanan yang baik dan lebih berkualitas. Ketidakpuasan yang diketahui oleh pelanggan terhadap suatu bentuk pelayanan yang diberikan oleh perusahaan dapat mengindikasikan bahwa pelayanan tersebut dilakukan secara tidak efektif dan efisien (Widyanita, 2018). Pada penelitian ini menggunakan sampel daerah kota cilegon banten yang memiliki jumlah penduduk modern yang cukup banyak ditambah kota tersebut memiliki perusahaan multi international. Menurut grafik hasil survei Snapcart Kota Cilegon 2019: 


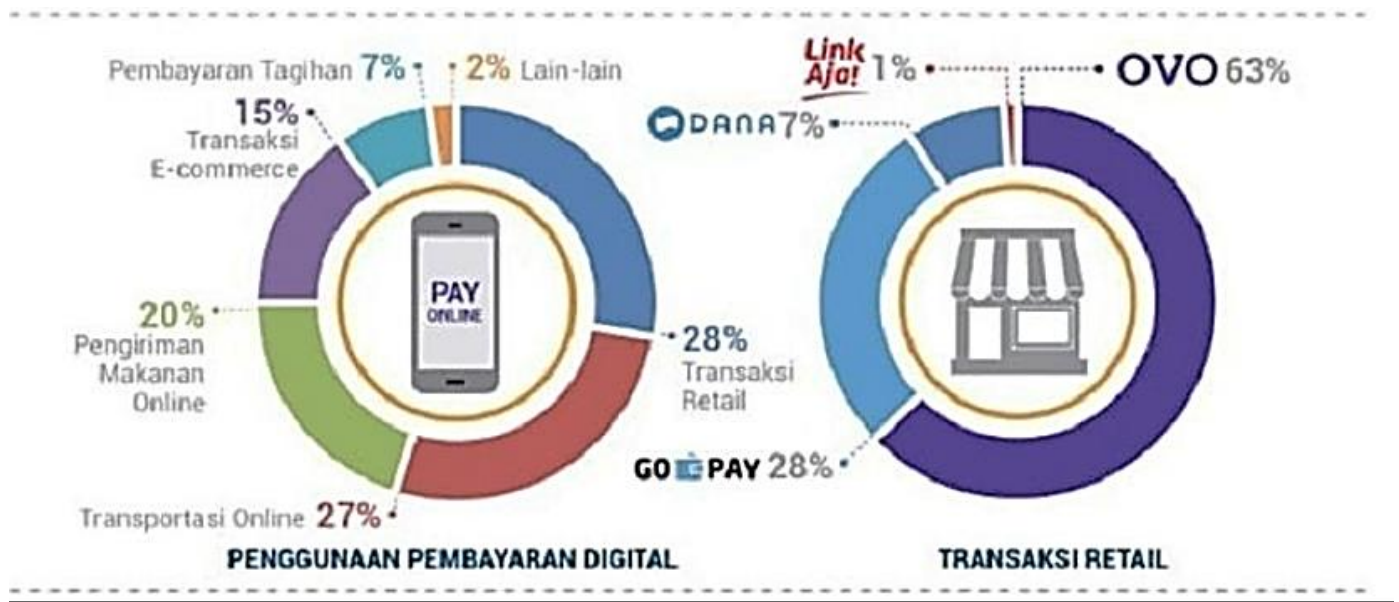

Gambar 1. Grafik hasil survei Snapcart kota Cilegon 2019

Hasil penelitian di daerah Cilegon mengungkapkan bahwa aplikasi pembayaran digital yang menjadi favorit adalah brand OVO yaitu sebanyak $64 \%$ responden. Sedangkan aplikasi pembayaran lain yaitu Go-Pay memiliki 28\% responden , Aplikasi Dana memiliki 9\% responden. Dari hasil riset ini dapat disimpulkan bahwa Brand OVO sudah melekat di benak konsumen di daerah Cilegon serta Brand Awareness yang baik di mata pelanggan yang angkanya mencapai $64 \%$. Layanan pembayaran $e$-Wallet (electronic wallet) merupakan sarana jasa dengan sistem yang mampu melakukan berbagai transaksi seperti pembayaran menggunakan fasilitas smartphone. Dengan kata lain, aplikasi $E$-Wallet dengan menggunakan smartphone dapat dianalogikan sebagai dompet mobile. DANA merupakan salah satu aplikasi $e$-wallet yang mendukung transaksi pembayaran non-tunai. DANA merupakan pendatang baru yang diresmikan pada Mei 2018. Fakta data iPrice Group, Aplikasi DANA berada di peringkat 2 di kuartal II 2019 menggeserkan LinkAja di posisi ketiga, dompet digital ini menggunakan layanan berbasis open platform yang canggih. DANA dapat dimanfaatkan dalam transaksi jasa, makanan, hiburan, dan pembayaran digital lainnya.

Kualitas layanan DANA dalam mempertahankan keunggulan kompetitif terhadap sebuah strategis untuk kesuksesan jangka panjang, dan penentu utama kepuasan pelanggan sehingga imbas kepada tingginya market share jasa. Tingkat tertinggi layanan sangat penting dalam loyalitas pelanggan dalam jangka yang panjang. Jika perusahaan miliki layanan yang luar biasa dapat meningkatkan performa anggaran perusahaan (Widyanita, 2018).

Saat ini Aplikasi DANA sedang meningkatkan keinginan pelanggan agar pengguna jasa layanan aplikasi DANA selalu setia pada aplikasi DANA sebagai transaksi pembayaran online, dengan menggunakan fitur Premium pelanggan mendapatkan banyak sekali keuntungan yaitu kemudahan pembayaran dan fitur yang di berikan lebih maksimal. Dana merupakan pembayaran $e$-wallet yang masih tergolong sangat baru dimasyarakat. Jika DANA mampu memberikan pelayan yang baik dan sesuai harapan, maka DANA akan memiliki persepsi baik di mata konsumen. Selain itu, jika mampu menghasilkan layanan yang baik, maka perusahaan dapat mencapai harapan konsumen serta memberikan pelayanan yang memuaskan. Jika Aplikasi DANA belum maksimal dalam memberikan informasi sehingga konsumen tidak Mengetahui adanya promo-promo di aplikasi DANA. Metode yang cukup optimal untuk masalah ini adalah metode Importance Performance Analysis (IPA) dan Customer Satisfaction Index (CSI) di karenakan Metode ini memiliki efisiensi, mudah digunakan dan sederhana serta menggunakan skala yang sensitive dan reliabilitas.. Metode pertama Customer Satisfaction Index (CSI) adalah indeks kepuasan pengguna yang diharapkan 
untuk mengetahui tingkat kepuasan konsumen secara keseluruhan dengan tingkat kepentingan dari layanan.

Satu strategi untuk analisis atribut oleh aplikasi ini adalah strategi pemasaran (7P) diantaranya product, price, place, promotion, people, process dan Physical Evidance (Dewi, 2019). Melalui strategi pemasaran ini akan menghasilkan atribut-atribut keinginan konsumen untuk penggunaan aplikasi DANA, sehingga digunakan metode Importance Performance Analysis (IPA), karena dapat mengetahui atribut yang ditingkatkan ataupun dikurangi untuk kepuasan konsumen, hasilnya yaitu dalam bentuk skala. Importance-Performance Analysis (IPA) adalah metode pertama kali diusulkan dan diperkenalkan untuk pengukuran tingkat kepuasan pelanggan.

\section{Tinjauan Pustaka}

\subsection{Jasa}

Jasa sebagai suatu aktivitas yang diperoleh satu pihak produsen yang tidak berwujud dan dapat dirasakan manfaatnya oleh konsumen Kotler dan Keller (2014) merupakan aktifitas yang diberikan oleh berbagai pihak yang bersifat intangible dan menyebabkan perpindahan kepemilikan. Menurut Kotler yang dikutip kembali oleh Tjijptono (2014), karakteristik jasa Terdiri dari :

1. Tak berwujud/Intangibility.

2. Jasa tak terpisahkan/Inseparability.

3. Bervariasi/Heterogeneity/variability/Inconsistency.

4. Tidak memiliki ketahanan yang lama/Perishability

5. Lack of Ownership

\subsection{Kualitas Pelayanan}

Kualitas ialah strategi untuk mendapatkan barang dan jasa untuk mencapai keinginan para pelanggan. ada beberapa persamaan dalam kualitas yaitu:

a. Meliputi usaha sesuai harapan pelanggan

b. Produk/jasa, manusia, proses dan lingkungan

c. Kondisi yang selalu berubah

\subsection{Kepuasan Pelanggan}

Perasaan seseorang dari hasil pembanding pada kinerja atau hasil suatu produk dan jasa. Kepuasan dibanyangi oleh pembanding layanan yang diharapkan, dan sebagai reaksi jangka yang sangat pendek konsumen pada kinerja pelayanan (Yuliati, 2016).

\subsection{Populasi dan Sampel}

Populasi diartikan semua objek yang diteiti yang memiliki karakter tertentu serta data yang menentukan keberhasilan penelitian, yang dijadikan populasi dalam penulisan ini adalah pengguna aplikasi DANA.

\subsubsection{Skala Pengukuran}

Pengukuran adalah satuan-satuan kuantitatif atau kualitatif pada objek penelitian, yang mengartikan jumlah atau tingkatan yang dimiliki objek tersebut. Untuk menghitung pengukuran dibutuhkan metode yaitu sebuah skala.

\subsection{Uji Validitas}

Angket tertulis valid jika angket mampu diketahui yang diukur (Ghozali, 2006). Metode yang untuk uji validitas adalah dengan korelasi antar skor yang ditanya dengan total variabelnya. Pada uji validitas ini terdapat dua rumus yaitu rumus uji validitas, nilai $r$ tabel tertulis rumus $d f=n-2$, sedangkan rumus $r$ hitung sebagai berikut (Putra, dkk. 2014): 
r hitung $=\frac{\mathrm{N} \sum \mathrm{x} \cdot \mathrm{y}-\left(\sum \mathrm{x}\right) \cdot\left(\sum \mathrm{y}\right)}{\sqrt{\left(\mathrm{N} \sum \mathrm{x}^{2}-\left(\sum \mathrm{x}\right)^{2}\right)\left(\mathrm{N} \sum \mathrm{y}^{2}-\left(\sum \mathrm{y}\right)^{2}\right)}}$

Keterangan:

$\mathrm{x}=$ nilai variabel

$\mathrm{y}=$ nilai keseluruhan variabel

$\mathrm{n}=$ Jumlah sampel

\subsection{CSI (Customer Satisfaction Index)}

Menurut Khairul (2018), Customer Satisfaction Index adalah menghitung tingkat kepuasan pengguna produk atau jasa dengan terlihat besaran kinerja dan besaran kepentingan atau harapan dari atribut jasa pelayanan. Untuk mengetahui nilai CSI, maka langkah-langkah yang dilakukan adalah sebagai berikut:

1. Menentukan Mode Importance Score (MIS)

2. Menghitung Weighting Factor (WF).

3. Menghitung Weighted Score (WS)

4. Menghitung Satisfaction Index (CSI)

Kriteria index kepuasan diantaranya 0,00 sampai 1,00 ) yang dapat dilihat pada tabel berikut :

Tabel 1. Kriteria index kepuasan

\begin{tabular}{cc}
\hline Nilai CSI & Kriteria CSI \\
\hline $0,81-1,00$ & Sangat Puas \\
$0,66-0,80$ & Puas \\
$0,51-0,65$ & Cukup Puas \\
$0,35-0,50$ & Kurang Puas \\
$0,00-0,34$ & Tidak Puas \\
\hline
\end{tabular}

\subsection{Importance Performance Analysis (IPA)}

Importance-Performance Analysis sebagai tahapan dan fasilitas untuk menghitung tingkatan kepuasan pelanggan terhadap produk atau jasa.



Gambar 2. Pembagian kuadran Importance-Performance Analysis (Maiyanti dkk, 2017)

Diagram ini (Gambar 2) terdiri dari empat kuadran, yaitu:

1. Kuadran I, wilayah tingkat kepentingan yang relatif tinggi.

2. Kuadran II, wilayah tingkat kepentingan relatif tinggi. 
3. Kuadran III, wilayah tingkat kepentingan yang relatif rendah dan kinerjanya kurang baik.

4. Kuadran IV, wilayah tingkat kepentingan yang relatif rendah dan pengguna terlalu berlebihan dengan tingkat kepuasan yang relatif tinggi. (Maiyanti, 2017)

Perhitungan IPA tentang kepuasan pelanggan terdapat dua komponen yaitu sangat berharganya produk atau layanan pelanggan dan kinerja bisnis dalam menyediakan layanan atau produk dalam memenuhi ekpektasi konsumen (Jesus dan Silva, 2011).

\subsection{Literatur Review}

Dalam penelitian ini lebih menekankan pengukuran kepuasan pelanggan dari kualitas pelayanan dan kinerjanya dengan sampel data yang diteliti adalah penggunaan Aplikasi DANA yang merupakan salah satu financial teknologi yang telah digunakan oleh konsumen di Indonesia lebih dari 3 tahun ini. Berbeda dengan penelitian sebelumnya lebih mengukur kualitas pelanggan dan kepuasan pelanggan dengan sampel perusahaan jasa dan manufaktur.

\section{Hasil dan Pembahasan}

\subsection{Metodologi Penelitian}

Penelitian ini membahas tentang kualitas jasa pelayanan terhadap kepuasan pelanggan pengguna aplikasi DANA atas pelayanan yang telah diberikan dan untuk mengetahui atribut apa saja yang harus diperbaiki berdasarkan metode IPA. Penelitian ini menggunakan metode pengumpulan data dengan menggunakan kuesioner kepada pengguna aplikasi DANA. Lokasi penelitian yang di gunakan di Kota Cilegon yang menggunakan aplikasi DANA premium dengan rentan umur 17 tahun - 65 tahun yang dilakukan secara online menggunakan link Goggle from dan angket yang tersebar di Kota Cilegon. Perancangan kuesioner ini dilakukan berdasarkan 7 dimensi yaitu efisiensi (efficiency), dimensi pemenuhan/jaminan (fulfillment), dimensi reliabilitas (reliability), dimensi privasi (privacy), dimensi daya tanggap (responsiveness), dimensi kompensasi (compensation) dan dimensi kontak (contact). karakteristik responden meliputi jenis kelamin, usia, pekerjaan, pendidikan terakhir. Dan Data Hasil Kuesioner Tingkat Kepentingan \& Tingkat Kepuasan Data yang pertama kali dikumpulkan yaitu hasil jawaban responden terhadap kuesioner tingkat kepentingan dan tingkat kepuasan, hasil kuesioner ini digunakan untuk mengolah data.

Adapun proses yang dilakukan adalah tentukan Mode Importance Score (MIS), nilai ini dari nilai dengan tingkat frekuensi yang besar dari tiap atribut, Menghitung Weighting Factor (WF), Menghitung Weighted Score (WS), Menghitung Customer Satisfaction Index (CSI). langkah awal dari proses pemecahan masalah menggunakan metode IPA. Proses yang dilakukan adalah menghitung seluruh hasil skor nilai kepuasan dan skor nilai kepentingan dari masing-masing kuesioner responden, Menghitung Nilai Kepuasan dan Nilai Kepentingan, Rata-Rata Skor Nilai Kepuasan dan Nilai Kepentingan, memetakan Hasil Tingkat Kesesuaian dan nilai Rata-Rata ke dalam Diagram Kartesius, dan menghitung hasil Atribut Pelayanan pada Empat Kuadran Metode IPA.

Penelitian ini mengolah data yang terdapat dalam kuesioner dan juga beberapa data pendukung lainnya. Untuk menentukan faktor-faktor yang menjadi prioritas dalam pemenuhan harapan pengguna aplikasi DANA, sebanyak 150 responden disebarkan sebagai kuesioner Pendahuluan dengan menggunakan rumus Lemeshow didapatkan nilai tingkat keyakinan 95\% dan nilai p 10\% maka terpilihlah sampel tersebut. tahap selanjutnya dilakukan pengambilan data kuesioner sesuai dengan jumlah sampel yang telah ditentukan. Data tersebut diuji validitas dan reliabilitas menggunakan syarat jika $t_{\text {hitung }}>t_{\text {tabel }}$ dan bila data tidak valid ataupun tidak reliabel maka akan kembali ke perancangan kuesioner selanjutnya yaitu langkah awal dari proses pemecahan masalah menggunakan metode CSI. Adapun proses menentukan Mode Importance Score (MIS), perhitungan Weighting Factor (WF), Weighted Score (WS), perhitungan nilai Customer Satisfaction Index (CSI), setelah itu melalukan pemilihan kriteria 
index berdasarkan hasil dari CSI. Selanjutnya yaitu langkah awal dari proses pemecahan masalah menggunakan metode IPA. Adapun proses yang dilakukan adalah menghitung seluruh hasil skor nilai kepuasan dan skor nilai kepentingan dari masing-masing kuesioner responden, perhitungan rata-rata total nilai tingkat kepuasan pada sumbu $(\mathrm{X})$ dan nilai tingkat kepentingan pada sumbu (Y) untuk menentukan atribut-atribut pada diagram kartesius, dan mengetahui hasil atribut pelayanan dalam empat kuadran Metode IPA

\subsection{Pengolahan Data}

Pada karakter orang yang digunakan dalam penelitian ini adalah konsumen pengguna Aplikasi DANA premium yang sudah lama menggunakan aplikasi tersebut. Dan dari hasil penyebaran kuesioner yang didapat menggunakan google from dan angket sebanyak 150 responden didapatkan dari karakteristik responden berdasarkan jenis kelamin, usia, tingkat pendidikan, dan pekerjaan responden. Tabel 2 menunjukkan hasil penelitian karakteristik responden pada jenis kelamin responden:

Tabel 2. Jenis kelamin responden

\begin{tabular}{|l|l|l|}
\hline Jenis Kelamin & Jumlah & $\begin{array}{l}\text { Persentase } \\
(\mathbf{\%})\end{array}$ \\
\hline Laki-laki & 27 & $18 \%$ \\
\hline Perempuan & 123 & $82 \%$ \\
\hline Total & $\mathbf{1 5 0}$ & $\mathbf{1 0 0 \%}$ \\
\hline
\end{tabular}

Tabel diatas dapat kita ketahui bahwa jumlah responen berdasarkan jenis kelamin dengan jumlah laki-laki 27 orang sedangkan jumlah penjawab perempuan sebanyak 123 orang, maka data yang diperoleh dapat dikatakan mayoritas konsumen dari pengguna Aplikasi DANA di Cilegon adalah perempuan.

Diketahui bahwa jumlah responen berdasarkan usia responden adalah usia 18 - 25 tahun terdiri $97 \%$, usia 26 - 35 tahun 3\%, dan untuk usia 36 - 45 tahun sebanyak $0 \%$, dan untuk usia $>55$ tahun sebanyak 0\%. maka dapat disimpulkan bahwa mayoritas pengguna Aplikasi DANA di Cilegon adalah kalangan anak muda. audient yang berstatus sebagai pelajar/mahasiswa sebanyak 133 orang, untuk yang bekerja sebagai Pegawai Negeri Sipil sebanyak 3 orang, untuk responden karyawan swasta sebanyak 6 orang, untuk responden wirausaha sebanyak 3 orang dan untuk responden ibu rumah tangga sebanyak 1 orang. dari data disimpulkan bahwa mayoritas pengguna Aplikasi DANA di Cilegon adalah pelajar/mahasiswa.

Data hasil kuesioner pada Metode IPA yang terdiri dari tingkat kepentingan dan tingkat kepuasan. Data ini diperoleh dari penyebaran kuesioner menggunakan google form kepada responden pengguna Aplikasi DANA di Cilegon. Berdasarkan tabel di bawah merupakan data hasil kuesioner pada tingkat kepentingan menggunakan metode IPA. Pada penelitian ini sampel yang digunakan sebanyak 150 sampel dengan menyebarkan kuesioner menggunakan google from kepada pengguna Aplikasi DANA dan angket secara offline. Setelah data yang sudah terkumpul, akan melakukan uji kecukupan data, uji validitas, dan uji reliabilitas 
KUALITAS PELAYANAN APLIKASI (Akbar G., dkk.)

Tabel 3. Data hasil kuesioner kepentingan dengan metode IPA

\begin{tabular}{|c|c|c|c|c|c|c|c|c|c|c|c|c|c|c|}
\hline \multirow{2}{*}{ No } & \multicolumn{14}{|c|}{ Pertanyaan } \\
\hline & $\mathrm{X} 1$ & $\mathrm{X} 2$ & X3 & $\mathrm{X} 4$ & $\mathrm{X} 5$ & X6 & $\mathrm{X} 7$ & X8 & $\mathrm{X} 9$ & $\mathrm{X} 10$ &. .5. & . & $\mathrm{X} 21$ & $\mathrm{X} 22$ \\
\hline 1 & 4 & 5 & 4 & 4 & 5 & 4 & 3 & 5 & 4 & 4 & & & 4 & 5 \\
\hline 2 & 4 & 4 & 4 & 5 & 5 & 4 & 4 & 4 & 5 & 5 & & & 5 & 3 \\
\hline 3 & 5 & 5 & 5 & 5 & 5 & 4 & 5 & 5 & 4 & 5 & & & 3 & 3 \\
\hline 4 & 4 & 4 & 4 & 5 & 5 & 4 & 4 & 4 & 3 & 5 & & & 4 & 4 \\
\hline 5 & 4 & 5 & 4 & 5 & 5 & 5 & 5 & 4 & 5 & 5 & & & 5 & 4 \\
\hline 6 & 4 & 3 & 4 & 5 & 4 & 4 & 5 & 3 & 3 & 5 & & & 3 & 3 \\
\hline 7 & 4 & 5 & 5 & 5 & 5 & 4 & 5 & 4 & 4 & 5 & & & 4 & 4 \\
\hline 8 & 4 & 5 & 4 & 5 & 5 & 4 & 4 & 4 & 3 & 5 & & & 4 & 4 \\
\hline 9 & 4 & 4 & 3 & 5 & 5 & 4 & 3 & 3 & 3 & 4 & & & 5 & 4 \\
\hline 10 & 4 & 4 & 5 & 5 & 5 & 5 & 5 & 5 & 3 & 5 & & & 5 & 5 \\
\hline . & & & & & & & & & & & & & & \\
\hline . & & & & & & & & & & & & & & \\
\hline . & & & & & & & & & & & & & & \\
\hline 149 & 4 & 4 & 4 & 4 & 4 & 4 & 4 & 4 & 5 & 4 & & & 4 & 3 \\
\hline 150 & 5 & 4 & 4 & 5 & 5 & 5 & 3 & 5 & 4 & 4 & & & 4 & 4 \\
\hline$\sum \mathrm{X}$ & 691 & 658 & 648 & 705 & 689 & 629 & 656 & 608 & 611 & 685 & & & 635 & 618 \\
\hline
\end{tabular}

Pada tahapan ini dilakukan sampel untuk menghitung berapa sampel yang diapilih sebelum data angket diolah dengan cara perhitungan Customer Satisfaction Index (CSI) dan Importance Performance Analysis (IPA).

$\mathrm{n}=\underline{\mathrm{Z}^{2}} \underline{\mathrm{pq}}$

$\mathrm{n}=\underline{(1,96)^{2}(0,5)(0,5)}$

$(0,1)^{2}$

$\mathrm{n}=96,04 \sim 100$

$\mathrm{n}$ : Sampel yang diperlukan

$\mathrm{z}$ : Tingkat keyakinan $95 \%$

$\mathrm{p}$ : Peluang benar $50 \%$

$\mathrm{q}$ : Peluang salah $50 \%$

e : Tingkat kesalahan sampel (sampling error) $10 \%(0.1)$

Berdasarkan rumus diatas, sampel diambil sebanyak 96,04 orang untuk memudahkan dalam perhitungan maka di bulatkan menjadi 100 orang dan sampel penelitian ini adalah pengguna Aplikasi DANA dimana jumlah sampel berdasarkan rumus Cochran (Sugiyono, 2018) yang diambil $<100$ responden

Metode yang akan digunakan untuk melakukan uji validitas adalah dengan melakukan korelasi antar skor butir pertanyaan dengan total skor konstruk atau variabel. Untuk menghasilkan valid dari instrument pada pengumpulan data didapat dengan cara korelasi skor variable jawaban responden dengan total skor masing-masing variable, selanjutnya korelasi dibanding dengan skor variable, kemudian hasil dibandingkan dengan nilai kritis pada taraf signifikan 0,05 dan 0,01 . Pada uji validitas ini terdapat dua rumus yaitu rumus uji validitas dengan nilai $r$ tabel menggunakan rumus $d f=n-2$, sedangkan rumus $r$ hitung sebagai berikut (Putra, dkk. 2014): 
r hitung $=\frac{\mathrm{N} \sum \mathrm{x} \cdot \mathrm{y}-\left(\sum \mathrm{x}\right) \cdot\left(\sum \mathrm{y}\right)}{\sqrt{\left(\mathrm{N} \sum \mathrm{x}^{2}-\left(\sum \mathrm{x}\right)^{2}\right)\left(\mathrm{N} \sum \mathrm{y}^{2}-\left(\sum \mathrm{y}\right)^{2}\right)}}$

Keterangan :

$\mathrm{x}=$ Skor variabel

$\mathrm{y}=$ Skor total variabel

$\mathrm{n}=$ Jumlah sampel

Berdasarkan hasil yang diperoleh, bahwa semua pertanyaan valid yaitu ada 22 pertanyaan yang diajukan kepada responden. Apabila uji validitas dikatakan valid jika, $\mathbf{r}_{\text {hitung }}>\mathbf{r}_{\text {tabel, }}$ maka pertanyaan signifikan terhadap skor total dinyatakan valid. Oleh karena itu, hasil yang diperoleh pada 22 item pertanyaan yang diteliti lebih dari $0,159\left(\mathbf{r}_{\text {hitung }}>\mathbf{r}_{\text {tabel }}\right)$ sehingga data responden pada tingkat kepentingan yang digunakan dalam penelitian ini dikatakan valid dan layak digunakan sebagai alat ukur variabel yang diteliti ditambah penyesuaian dari hasil kuesioner yang telah di validasi dari peneliti terdahulu.

Mengukur tingkat kepuasan konsumen dengan membuat Customer Satisfaction Index (CSI). Perhitungan pada kepuasan pelanggan untuk mengetahui hasil konsumen setelah mengonsumsi produk dan jasa produsen sehingga dapat menentukan sasaran akan datang selanjutnya digunakan metode Customer Satisfaction Index (CSI) untuk memperhitungkan rata-rata tingkat kepentingan dan skor rata-rata tingkat kepuasan untuk pengguna Aplikasi DANA. Berikut ini merupakan data hasil kuesioner menggunakan metode CSI (Customer Satification Index) yang terdiri dari Mean Importance Score (MIS), Mean Satisfaction Score (MSS), Weighted Score (WS) dan Weighted Factor (WF). Data ini diperoleh dari penyebaran kuesioner menggunakan google from kepada responden pengguna Aplikasi DANA di Cilegon yaitu sebagai berikut:

Tabel 4. Data hasil kuesioner metode CSI

\begin{tabular}{|l|c|c|c|c|}
\hline \multicolumn{1}{|c|}{ Pertanyaan } & $\begin{array}{c}\text { Mean } \\
\text { Importance } \\
\text { Score }\end{array}$ & $\begin{array}{c}\text { Weighting } \\
\text { Factors } \\
(\%)\end{array}$ & $\begin{array}{c}\text { Mean } \\
\text { Satisfaction } \\
\text { Score }\end{array}$ & $\begin{array}{c}\text { Weighted } \\
\text { Score }\end{array}$ \\
\hline $\begin{array}{l}\text { Tampilan aplikasi DANA mudah } \\
\text { atau user friendly }\end{array}$ & 4.61 & 4.82 & 3.95 & 19.03 \\
\hline $\begin{array}{l}\text { Kemudahan dalam melakukan } \\
\text { transaksi }\end{array}$ & 4.39 & 4.59 & 3.63 & 16.68 \\
\hline $\begin{array}{l}\text { Kemudahan dalam mengakses } \\
\text { fasilitas }\end{array}$ & 4.32 & 4.52 & 4.03 & 18.24 \\
\hline $\begin{array}{l}\text { Banyak vendor yang bekerjasama } \\
\text { dengan aplikasi DANA }\end{array}$ & 4.70 & 4.92 & 4.10 & 20.17 \\
\hline $\begin{array}{l}\text { Untuk memuat halaman Aplikasi } \\
\text { DANA tidak membutuhkan waktu } \\
\text { yang lama }\end{array}$ & 4.59 & 4.81 & 4.21 & 20.22 \\
\hline $\begin{array}{l}\text { Aplikasi DANA update dalam } \\
\text { memberikan informasi terbaru }\end{array}$ & 4.19 & 4.39 & 3.61 & 15.83 \\
\hline $\begin{array}{l}\text { Aplikasi DANA selalu memberikan } \\
\text { notifikasi ketika merilis informasi } \\
\text { terbaru }\end{array}$ & 4.37 & 4.58 & 3.65 & 16.72 \\
\hline $\begin{array}{l}\text { Seringkali memberikan potongan } \\
\text { harga atau kupon }\end{array}$ & 4.05 & 4.24 & 3.75 & 15.92 \\
\hline
\end{tabular}


KUALITAS PELAYANAN APLIKASI (Akbar G., dkk.)

Tabel 4. Data hasil kuesioner metode CSI (lanjutan)

\begin{tabular}{|l|c|c|c|c|}
\hline \multicolumn{1}{|c|}{ Pertanyaan } & $\begin{array}{c}\text { Mean } \\
\text { Importance } \\
\text { Score }\end{array}$ & $\begin{array}{c}\text { Weighting } \\
\text { Factors } \\
\text { (\%) }\end{array}$ & $\begin{array}{c}\text { Mean } \\
\text { Satisfaction } \\
\text { Score }\end{array}$ & $\begin{array}{c}\text { Weighted } \\
\text { Score }\end{array}$ \\
\hline $\begin{array}{l}\text { Informasi yang ada pada Aplikasi } \\
\text { DANA terorganisasi dengan BAIK }\end{array}$ & 4.07 & 4.26 & 3.65 & 15.57 \\
\hline $\begin{array}{l}\text { Kesigapan dalam membantu } \\
\text { pelayanan }\end{array}$ & 4.57 & 4.78 & 3.54 & 16.92 \\
\hline $\begin{array}{l}\text { Aplikasi DANA memiliki tampilan } \\
\text { yang indah }\end{array}$ & 4.29 & 4.49 & 3.61 & 16.21 \\
\hline $\begin{array}{l}\text { Transaksi dalam Aplikasi DANA } \\
\text { mudah dilakukan }\end{array}$ & 4.31 & 4.51 & 3.81 & 17.16 \\
\hline $\begin{array}{l}\text { Tersedianya Call Centre 24 jam } \\
\text { untuk melayani konsumen }\end{array}$ & 4.11 & 4.31 & 3.84 & 16.53 \\
\hline $\begin{array}{l}\text { Customer service yang melayani } \\
\text { keluhan dengan baik dan cepat }\end{array}$ & 4.13 & 4.33 & 3.68 & 15.92 \\
\hline $\begin{array}{l}\text { Anda tidak mengalami kesulitan } \\
\text { ketika melakukan top up saldo } \\
\text { Aplikasi DANA }\end{array}$ & 4.12 & 4.31 & 3.78 & 16.30 \\
\hline $\begin{array}{l}\text { Anda juga dapat melakukan top up } \\
\text { saldo Aplikasi DANA melalui } \\
\text { agen (alfamart, indomaret, dandan, } \\
\text { dll) dan sistem online. }\end{array}$ & 4.32 & 4.52 & 3.99 & 18.06 \\
\hline Data pribadi konsumen terlindungi & 4.29 & 4.49 & 3.89 & 17.49 \\
\hline $\begin{array}{l}\text { Anda merasa lebih aman saat } \\
\text { bertransaksi menggunakan Aplikasi } \\
\text { DANA }\end{array}$ & 4.61 & 4.83 & 4.10 & 19.80 \\
\hline $\begin{array}{l}\text { DANA menyediakan jaminan } \\
\text { keamanan yang tegas terhadap } \\
\text { privasi konsumen }\end{array}$ & 4.59 & 4.80 & 4.01 & 19.27 \\
\hline $\begin{array}{l}\text { Anda dapat menyimpan saldo lebih } \\
\text { dari Rp1.000.000,- dalam Aplikasi } \\
\text { DANA }\end{array}$ & 4.55 & 4.76 & 4.05 & 17.26 \\
\hline $\begin{array}{l}\text { Anda merasa menggunakan } \\
\text { Aplikasi DANA sangat } \\
\text { menyenangkan (fun) }\end{array}$ & 4.23 & 4.43 & 4.03 & 7.14 \\
\hline $\begin{array}{l}\text { Layanan Aplikasi DANA memiliki } \\
\text { reputasi kejujuran yang baik dan } \\
\text { dapat dipercaya }\end{array}$ & 4.12 & 100.00 & & \\
\hline Total & & & & 17.84 \\
\hline
\end{tabular}

Hasil pengolahan data dengan menggunakan metode IPA melalui tahapan menghitung nilai skor dari data tingkat kepentingan dan tingkat kepuasan. Selanjutnya dilanjutkan dengan menghitung nilai tingkat kesesuaian atribut dan nilai rata-rata skor tingkat kepentingan dan tingkat kepuasan yang kemudian akan di petakan kedalam diagram kartesius menggunakan bantuan software SPSS 21. 
Tabel 5. Hasil skor kepentingan dengan metode IPA



Berdasarkan tabel diatas dapat diketahui bahwa hasil skor pada tingkat kepentingan untuk atribut 1 dari 150 responden yang terdiri dari 22 atribut 1 berjumlah 691 dengan menggunakan metode IPA. Berikut ini adalah tabel hasil skor tingkat kepuasan yaitu:

Tabel 6. Hasil skor kepuasan dengan metode IPA

\begin{tabular}{|c|c|c|c|c|c|c|c|c|c|c|c|c|c|c|}
\hline \multirow{2}{*}{ No } & \multicolumn{14}{|c|}{ Pertanyaan } \\
\hline & $\mathrm{X} 1$ & $\mathrm{X} 2$ & X3 & $\mathrm{X} 4$ & $\mathrm{X5}$ & X6 & X7 & $\mathrm{X} 8$ & X9 & X10 & & & X21 & $\mathrm{X} 22$ \\
\hline 1 & 3 & 2 & 3 & 3 & 3 & 3 & 2 & 3 & 4 & 3 & & & 3 & 2 \\
\hline 2 & 3 & 3 & 4 & 4 & 5 & 3 & 4 & 2 & 4 & 3 & & & 3 & 4 \\
\hline 3 & 4 & 5 & 4 & 4 & 4 & 3 & 3 & 4 & 2 & 2 & & & 5 & 3 \\
\hline 4 & 3 & 4 & 5 & 5 & 5 & 4 & 5 & 5 & 3 & 2 & & & 3 & 3 \\
\hline 5 & 4 & 4 & 5 & 5 & 4 & 4 & 4 & 4 & 5 & 4 & & & 3 & 3 \\
\hline 6 & 5 & 5 & 5 & 5 & 4 & 4 & 4 & 4 & 4 & 4 & & & 5 & 4 \\
\hline 7 & 3 & 2 & 3 & 3 & 3 & 3 & 3 & 4 & 4 & 5 & & & 4 & 4 \\
\hline 8 & 4 & 5 & 5 & 5 & 5 & 4 & 4 & 4 & 4 & 4 & & & 4 & 4 \\
\hline 9 & 4 & 4 & 4 & 4 & 4 & 4 & 4 & 4 & 4 & 4 & & & 4 & 4 \\
\hline 10 & 4 & 2 & 5 & 4 & 4 & 3 & 3 & 3 & 4 & 2 & & & 5 & 5 \\
\hline . & & & & & & & & & & & & & & \\
\hline . & & & & & & & & & & & & & & \\
\hline 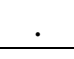 & & & & & & & & & & & & & & \\
\hline 149 & 4 & 5 & 4 & 5 & 5 & 4 & 5 & 3 & 4 & 5 & & & 4 & 4 \\
\hline 150 & 4 & 4 & 3 & 5 & 3 & 4 & 3 & 2 & 4 & 4 & & & 4 & 4 \\
\hline$\sum \mathrm{X}$ & 592 & 545 & 605 & 615 & 631 & 541 & 548 & 563 & 548 & 531 & & & 605 & 576 \\
\hline
\end{tabular}

Berdasarkan tabel diatas dapat diketahui bahwa hasil skor pada tingkat kepuasan untuk atribut 1 dari 150 responden yang terdiri dari 22 atribut berjumlah 592 dengan menggunakan metode IPA. Berikut ini adalah merupakan hasil perhitungan yang digunakan untuk urutan unggulan. 
Tabel 7. Tingkat kesesuaian

\begin{tabular}{|c|c|c|c|}
\hline Atribut & $\begin{array}{c}\text { Skor Tingkat } \\
\text { Kepuasan }(X)\end{array}$ & $\begin{array}{c}\text { Skor Tingkat } \\
\text { Kepentingan (Y) }\end{array}$ & $\begin{array}{c}\text { Tingkat Kesesuaian } \\
(\%)\end{array}$ \\
\hline $\mathrm{X} 1$ & 592 & 691 & 85.67 \\
\hline $\mathrm{X} 2$ & 545 & 658 & 82.83 \\
\hline $\mathrm{X} 3$ & 605 & 648 & 93.36 \\
\hline $\mathrm{X} 4$ & 615 & 705 & 87.23 \\
\hline $\mathrm{X} 5$ & 631 & 689 & 91.58 \\
\hline $\mathrm{X} 6$ & 541 & 629 & 86.01 \\
\hline $\mathrm{X} 7$ & 548 & 656 & 83.54 \\
\hline $\mathrm{X} 8$ & 563 & 608 & 92.60 \\
\hline X9 & 548 & 611 & 89.69 \\
\hline $\mathrm{X} 10$ & 531 & 685 & 77.52 \\
\hline $\mathrm{X} 11$ & 541 & 644 & 84.01 \\
\hline $\mathrm{X} 12$ & 571 & 646 & 88.39 \\
\hline $\mathrm{X} 13$ & 576 & 617 & 93.35 \\
\hline $\mathrm{X} 14$ & 552 & 620 & 89.03 \\
\hline $\mathrm{X} 15$ & 567 & 618 & 91.75 \\
\hline $\mathrm{X} 16$ & 599 & 648 & 92.44 \\
\hline $\mathrm{X} 17$ & 584 & 644 & 90.68 \\
\hline $\mathrm{X} 18$ & 615 & 692 & 88.87 \\
\hline X19 & 602 & 688 & 87.50 \\
\hline $\mathrm{X} 20$ & 607 & 682 & 89.00 \\
\hline $\mathrm{X} 21$ & 605 & 635 & 95.28 \\
\hline $\mathrm{X} 22$ & 576 & 618 & 93.20 \\
\hline Rata-rata & & 92.59 & \\
\hline
\end{tabular}

Berdasarkan tabel diatas bahwa hasil tingkat ketepatan pada kinerja dengan kepentingan pelanggan, maka didapatkan hasil tingkat kesesuaian yaitu sebesar $85.67 \%$, dengan nilai ratarata tingkat kesesuaian seluruh atribut pertanyaan sebesar $92.59 \%$. Setelah itu nilai dibandingkan tingkat kesesuaian, apabila tingkat kesesuaian lebih kecil dari pada nilai suatu keputusan maka atribut perlu ada perbaikan dan jika kesesuaian lebih besar daripada pengambilan keputusan maka atribut perlu dipertahankan. Berikut ini adalah hasil perhitungan rata-rata skor dari tingkat kepentingan dan tingkat kepuasan yaitu :

Tabel 8. Rata-rata skor tingkat kepentingan dan kepuasan

\begin{tabular}{|c|c|c|}
\hline Atribut & $\begin{array}{c}\text { Rata-rata Skor Tingkat } \\
\text { Kepuasan }(\mathrm{X})\end{array}$ & $\begin{array}{c}\text { Rata-rata Skor Tingkat } \\
\text { Kepentingan (Y) }\end{array}$ \\
\hline 1 & 3.95 & 4.61 \\
\hline 2 & 3.63 & 4.39 \\
\hline 3 & 4.03 & 4.32 \\
\hline 4 & 4.10 & 4.70 \\
\hline 5 & 4.21 & 4.59 \\
\hline 6 & 3.61 & 4.19 \\
\hline 7 & 3.65 & 4.37 \\
\hline 8 & 3.75 & 4.05 \\
\hline
\end{tabular}


Tabel 8. Rata-rata skor tingkat kepentingan dan kepuasan (lanjutan)

\begin{tabular}{|c|c|c|}
\hline Atribut & $\begin{array}{c}\text { Rata-rata Skor Tingkat } \\
\text { Kepuasan (X) }\end{array}$ & $\begin{array}{c}\text { Rata-rata Skor Tingkat } \\
\text { Kepentingan (Y) }\end{array}$ \\
\hline 9 & 3.65 & 4.07 \\
\hline 10 & 3.54 & 4.57 \\
\hline 11 & 3.61 & 4.29 \\
\hline 12 & 3.81 & 4.31 \\
\hline 13 & 3.84 & 4.11 \\
\hline 14 & 3.68 & 4.13 \\
\hline 15 & 3.78 & 4.12 \\
\hline 16 & 3.99 & 4.32 \\
\hline 17 & 3.89 & 4.29 \\
\hline 18 & 4.10 & 4.61 \\
\hline 19 & 4.01 & 4.59 \\
\hline 20 & 4.05 & 4.55 \\
\hline 21 & 4.03 & 4.23 \\
\hline 22 & 3.84 & 4.12 \\
\hline Rata-rata & 3.85 & 4.34 \\
\hline
\end{tabular}

Pembuatan diagram tersebut memilah bagan menjadi empat bagian yang dipotong oleh dua garis berpotongan tegak lurus pada titik-titik X dan Y. Diagram kartesius dibuat menggunakan bantuan software SPSS 20.

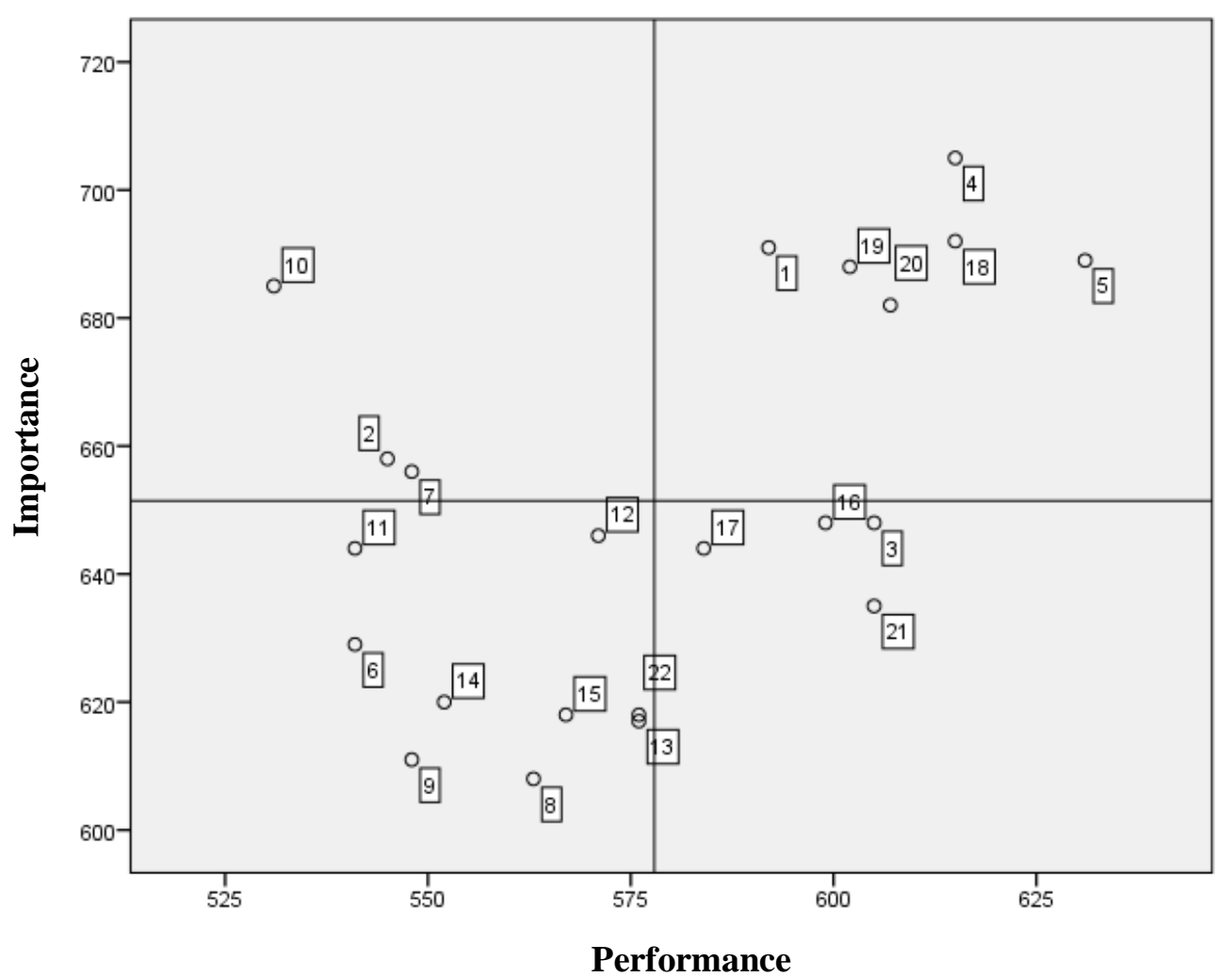

Gambar 3. Hasil Diagram Kartesius Metode IPA 


\subsection{Pembahasan}

Tingkat kepuasan konsumen Aplikasi DANA menggunakan metode Customer Satisfaction Index (CSI) yang diperoleh dari penelitian ini adalah sebesar 77,14. Nilai ini menunjukkan bahwa para pengguna merasa puas pada pelayanan dari Aplikasi DANA, karena indeks kepuasan berada pada rentang $0,66-0,80$. Indeks kepuasan konsumen yang berada pada level ini masih perlu untuk terus ditingkatkan, yaitu dengan cara melakukan perbaikan-perbaikan yang masih mungkin dilakukan berdasarkan analisa perhitungan pada setiap kuadran. Berdasarkan diagram Kartesiun pada gambar 3 menunjukkan bahwa kuadran I dan III merupakan prioritas utama untuk dilakukan perbaikan, sedangkan atribut pada kuadran II dapat dipertahankan. Peningkatan CSI dapat diupayakan hingga 100\% agar konsumen merasakan kepuasan pada level maksimal. Hal ini dapat dilakukan dengan dilakukan revisi pada atribut dari hasil diagram Kartesius menggunakan metode IPA (Muharastri, 2015). Upaya untuk meningkatkan CSI hingga 100\% pada Aplikasi DANA melalui perbaikan atribut perlu diupayakan secara serius sehingga pelanggan dapat merasakan bahwa kinerja atributatribut Aplikasi DANA sama dengan tingkatan kepentingan yang telah ditentukan.

Hasil perhitungan nilai rataan persepsi sebesar 3,85 dan harapan sebesar 4,19. Jika dihubungkan dengan pernyataan Anggraini (2017), bahwa metode Importance Performance Analysis (IPA) menghasilkan nilai rata untuk kepentingan dan kinerja, dan ditunjukkan melalui diagram IPA yang terbagi menjadi empat bagian. Rata-rata hasil penilaian konsumen terdapat ke dalam diagram Kartesius, dengan sumbu absis (X) adalah tingkat kepuasan dan sumbu ordinat (Y) adalah tingkat kepentingan. Matriks ini menunjukkan atribut tertentu yang perlu dipertahankan dan atribut mana yang dilakukan perbaikan. Metode IPA menghasilkan matriks yang berisikan 4 kuadran, yaitu Kuadran 1 (Prioritas Utama) merupakan tempat yang terdiri atribut dengan tingkatan kepentingan yang tinggi tetapi tingkat kepuasan rendah sehingga kenyataannya belum sesuai dengan harapan pelanggan. Selanjutnya Kuadran 2 (Pertahankan Kinerja) merupakan daerah yang terdiri atribut dengan tingkatan kepentingan tinggi dan tingkatan kinerja/kenyataan yang sama tinggi. Selanjutnya Kuadran 3 (Prioritas Rendah) merupakan daerah yang memuat atribut-atribut dengan tingkat kepentingan yang rendah dan tingkat kepuasan pun rendah. Selanjutnya Kuadran 4 (Berlebihan) merupakan daerah yang terdiri atribut dengan tingkatan kepentingan yang rendah dan tingkatan kepuasan yang tinggi.

Berdasarkan diagram Kartesius yang diperoleh menunjukkan bahwa adanya atribut-atribut yang perlu diperbaiki dan atribut-atribut perlu untuk dperlu dipertahankan. Diagram ini terbagi ke dalam 4 kuadran (I, II, III dan IV) dengan tingkat kesesuain antara tingkat kepentingan pelanggan dan kinerja perusahaan sebesar 92,59. Dengan memperhatikan masing-masing kuadran yang terdapat dalam diagram Kartesius, Aplikasi DANA dapat meningkatkan kualitas pelayanan dengan cara segera melakukan perbaikan pada atribut-atribut yang dianggap penting oleh konsumen dalam waktu singkat.

Tingkat kepuasan yang masih sangat rendah ditemukan pada kuadran I, sehingga atributatribut yang ada di dalamnya menjadi pemikiran utama untuk melakukan perbaikan. Atribut 10, 2, dan 7 ada di kuadran I.

1. Atribut 10 menunjukkan kesigapan dalam membantu pelayanan dimana atribut ini termasuk ke dalam dimensi responsiveness (daya tanggap). Pelanggan Aplikasi DANA menilai bahwa kesigapan dalam membantu masih kurang. Hal ini dinilai dari lambatnya respon yang diberikan dari pusat bantuan di Aplikasi DANA, bahkan sering tidak ada balasan sama sekali. Beberapa pilihan bantuan sebenarnya sudah disediakan seperti call center, alamat email DANA, bahkan pelanggan dapat menghubungi pihak DANA melalui twitter dan facebook, tetapi responnya sangat lambat sehingga membuat pelanggan merasa tidak puas untuk menggunakan layanan ini. Cara yang dapat dilakukan oleh pihak Aplikasi DANA adalah dengan menyediakan tenaga administrasi lebih banyak agar cepat menangani keluhan yang dialami oleh pelanggan, sehingga masalah dapat segera teratasi. 
Kepedulian karyawan terhadap pelanggan dapat tercermin dari kemampuan karyawan dalam memperhatikan kebutuhan pelanggan (Assauri, 2017). Karyawan harus mempunyai kemampuan dan keterampilan dalam memberikan perhatian serta respon yang baik terhadap kebutuhan pelanggan, sehingga dapat menjadi satukunci sukses dalam memuaskan pelanggan.

2. Selanjutnya atribut yang harus diperbaiki yang dianggap kurang memuaskan pelanggan adalah atribut 2 yaitu kemudahan dalam melakukan transaksi, dimana atribut ini termasuk ke dalam dimensi Tangibles (Bukti Fisik). Kemudahan bertransaksi secara debit sudah memuaskan konsumen, namun terkadang konsumen ingin melakukan pembayaran di merchant yang bekerjasama pada Aplikasi DANA konsumen merasa sulit dalam melakukan pembayaran. Rahayu dkk (2013) menyatakan bahwa salah satu bentuk kegagalan dalam pelayanan adalah adanya kinerja yang dinilai atau dipersepsikan lambat oleh pelanggan dalam menjalankan tugas untuk memenuhi kebutuhan konsumen. Hal ini dapat mengakibatkan adanya rasa tidak puas dari pelanggan terhadap kualitas pelayanan yang diterima.

3. Atribut ketiga yang dianggap kurang memuaskan pelanggan adalah atribut 7 Aplikasi DANA selalu memberikan notifikasi ketika merilis informasi terbaru dimana atribut ini termasuk ke dalam dimensi Reliability. Pelanggan Aplikasi DANA menilai bahwa memberikan notifikasi ketika merilis informasi terbaru terkadang sangat terlambat dan tidak upgrade sehingga membuat pelanggan merasa tidak puas untuk menggunakan layanan Aplikasi di DANA ini. Cara yang dapat dilakukan oleh pihak Aplikasi DANA adalah dengan melakukan upgrade dalam hal informasi terkait adanya program promo, pemberlakuan cashback, serta event potongan harga yang dijalankan di beberapa merchant. Hal ini sangat perlu dilakukan agar konsumen selalu mendapatkan informasi terbaru dan tertarik untuk mengikuti program-program yang dilaksanakan.

Selanjutnya pada kuadran II (pertahankan kinerja/prestasi), merupakan kuadran yang perlu untuk dipertahankan oleh aplikasi DANA karena memberikan layanan dengan harapan pelanggan sehingga pelanggan merasa puas. Adapun atribut yang termasuk kedalam kuadran ini adalah 1, 4, 5, 18, 19, 20.

Berdasarkan hasil penelitian diperoleh bahwa skor pengambilan keputusan relatif lebih kecil dibandingkan dengan tingkat kesesuaian setiap atribut, sehingga tidak ada atribut yang perlu dilakukan perbaikan. Atribut 1 menunjukkan bahwa tampilan aplikasi DANA mudah atau user friendly, atribut 4 yaitu banyak vendor yang bekerjasama, atribut 5 memuat halaman tidak membutuhkan waktu yang lama, atribut 18 merasa lebih aman saat bertransaksi, atribut 19 menyediakan jaminan keamanan yang tegas terhadap privasi konsumen, atribut 20 menyimpan saldo lebih dari Rp 1.000.000,-. Untuk atribut 1, 4, dan 5 termasuk atribut dimensi Tangibles (Bukti Fisik), atribut 18, 19, dan 20 termasuk atribut dimensi Assurance (Jaminan).

Selanjutnya pada kuadran III (prioritas rendah), atribut kuadran ini memberikan pengaruh yang sangat kecil pada manfaat yang dirasakan oleh pengguna Aplikasi DANA sehingga perlu diperbaiki kinerja juga kepentingannya. Terdapat 9 atribut dalam kuadran 3 ini yang merupakan prioritas rendah. Adapun atribut kuadran ini adalah 6, 8, 9, 11, 12, 13, 14, 15, dan 22. Atribut yang pertama yaitu atribut 6 Update dalam memberikan informasi terbaru, atribut 8 yaitu Seringkali memberikan potongan harga atau kupon, atribut 9 yaitu Informasi yang ada pada Aplikasi DANA terorganisasi dengan BAIK, atribut 11 yaitu Aplikasi DANA memiliki tampilan yang menarik, atribut 12 yaitu Transaksi mudah dilakukan, atribut 13 yaitu adanya Call Centre 24 jam untuk melayani konsumen, atribut 14 yaitu Customer service yang dapat mengetahui keluhan dengan baik dan cepat, atribut 15 yaitu Anda tidak mengalami kesulitan ketika melakukan top up saldo Aplikasi DANA, dan atribut 22 yaitu Layanan memiliki reputasi kejujuran yang baik dan dapat dipercaya. Untuk atribut 6, 8, dan 9 adalah termasuk 
atribut dimensi keandalan (Reliability), atribut 11, 12, 13, 14, dan 15 termasuk atribut dimensi daya tanggap (Responsiveness), dan atribut 22 termasuk atribut dimensi perhatian (Emphaty).

Selanjutnya pada kuadran IV (berlebihan), atribut kuadran ini tidak terlalu harus diperbaiki di mata pelanggan, namun memuaskan pelanggan pengguna aplikasi dana. Terdapat 4 atribut dalam kuadran 4 ini yang merupakan berlebihan seperti atribut 3 yaitu kemudahan dalam mengakses fasilitas, atribut 16 yaitu anda juga dapat melakukan top up saldo aplikasi dana melalui agen (Alfamart, Indomaret, dandan, dll) dan sistem online, atribut 17 yaitu data pribadi konsumen terlindungi, dan atribut 21 anda merasa menggunakan aplikasi dana sangat menyenangkan (fun).

\section{Kesimpulan}

Hasil yang telah dilakukan dapat diketahui Metode Customer Satisfaction Index (CSI) dan diperoleh nilai CSI sebesar 77,1\% ialah pada range 0,66-0,80. Dapat disimpulkan bahwa secara keseluruhan bahwa pelanggan puas terhadap kinerja dari atribut tersebut. Kualitas pelayanan pada Aplikasi DANA belum sesuai kebutuhan dan keinginan konsumen. Tidak sesuainya kebutuhan dan keinginan pelanggan terlihat oleh atribut yang berada ke dalam kuadran I pada diagram kartesius, yaitu : atribut kesigapan dalam membantu pelayanan, atribut kemudahan dalam melakukan transaksi, atribut aplikasi dana selalu memberikan notifikasi ketika merilis informasi terbaru. Kesigapan dalam membantu pelayanan dimana atribut ini termasuk ke dalam dimensi responsiveness (daya tanggap). Pelanggan Aplikasi DANA menilai bahwa kesigapan dalam membantu masih kurang karena pusat bantuan di Aplikasi DANA ini responnya sangat lambat bahkan tidak ada balasan dari pihak Aplikasi DANA, padahal sudah tersedia beberapa pilihan bantuan seperti Call Center, alamat email DANA, menghubungi pihak DANA melalui via twitter dan facebook tetapi responnya sangat lambat sehingga membuat pelanggan merasa tidak puas untuk menggunakan layanan Aplikasi di DANA ini. Cara yang dapat dilakukan oleh pihak Aplikasi DANA seperti lebih banyak admin yang dapat cepat menangani keluhan yang dialami oleh pelanggan, sehingga keluhan pelanggan dapat teratasi. Selanjutnya atribut yang harus diperbaiki adalah atribut 2 yaitu kemudahan dalam melakukan transaksi dimana atribut ini termasuk ke dalam dimensi Tangibles (Bukti Fisik) Kemudahan dalam pembayaran dari segi transaksi debit sudah memuaskan konsumen, namun terkadang konsumen ingin melakukan pembayaran di merchant yang bekerjasama pada Aplikasi DANA konsumen merasa sulit dalam melakukan pembayaran. Atribut 7 yaitu Aplikasi DANA selalu memberikan notifikasi ketika merilis informasi terbaru dimana atribut ini termasuk ke dalam dimensi Reliability.

Dapat diketahui bahwa kualitas pelayanan pada Aplikasi DANA untuk faktor yang harus diprioritaskan agar dapat memenuhi harapan pengguna aplikasi DANA ditunjukan adanya atribut yang berada di kuadaran II diagram kartesius, yaitu: tampilan aplikasi DANA mudah atau user friendly, banyak vendor yang bekerjasama, memuat halaman tidak membutuhkan waktu yang lama, merasa lebih aman saat bertransaksi, menyediakan jaminan keamanan yang tegas terhadap privasi konsumen, menyimpan saldo lebih dari Rp1.000.000,-

\section{Daftar Pustaka}

Afifudin (2017) Dasar-dasar manajemen. Alfabeta. Bandung

Andry, J. F. (2019) 'Analisis kualitas website menggunakan metode Webqual 4.0 pada e commerce JD. ID', Jurnal Ilmiah Teknologi Informasi Terapan, Vol. IV, No .3.

Anggraini, L. D. dkk. (2018) 'The analysis of consumer perception used Importance Performance Analysis Method and Customer Satisfaction Index', Jurnal Industri. Vol. 4, No. 2 , hal $74-81$ 
Anjelina (2018) 'Persepsi konsumen pada penggunaan e-money', Journal of Applied Managerial Accounting, Vol. 2, No. 2, hal 219-231

Drost, E. (2011) 'Validity and reliability in social science research', International Perspectives on Higher Education Research, Los Angeles: California State University.

Fadhillah, M. A. (2012) 'Analisis kinerja perusahaan dilihat dari kepuasan pelanggan pada perusahaan kontraktor telekomunikasi dengan menggunakan pendekatan metode B2b Servqual dan Importance Performance Analysis (IPA)', Skripsi, Universitas Indonesia, Depok.

Ghozali, Imam (2011) Aplikasi analisis multivariate dengan program SPSS. Badan Penerbit Universitas Diponegoro. Semarang.

Jayaningrum, V. A. (2019) 'Analisis faktor-faktor yang mempengaruhi penerimaan dan penggunaan mobile payment pada teknologi pembayaran OVO', Skripsi, Universitas Sanata Dharma, Yogyakarta.

Jesus, F. D, dan Silva, H. (2011) 'Importance Performance Analysis as a tool in evaluating higher education service quality : the empirical results of estig ( IPB )', hal 306-315.

Kotler. Philip. Kevin. L. Keller (2014) Marketing management $15^{\text {th }}$ edition. Global Edition. England: Pearson Education Limited.

Lubis, S N, Fauzia, L and Utam, D. (2020) CSI (Customer Satisfaction Index) and IPA (Importance Performance Analysis) of Mandheling Coffee in Medan, Department of Agribusiness, Faculty of Agriculture. Medan:Universitas Sumatera Utara.

Maiyanti. S. I. dkk. (2017) 'Applied Customer Satisfaction Index (CSI) and ImportancePerformance Analysis (IPA) to know student satisfaction level of Sriwijaya University Library Services', Jurnal Industri. Vol. No. 2, hal $74-81$.

Mohajan, H. K. (2017) 'Two criteria for good measurements in research: validity and reliability Annals of Spiru Haret', Economic Series, Vol. 17, No. 4, hal 59.

Nugraha, Rizal, Harsono, A, Adianto, H. (2014) 'Usulan peningkatan kualitas pelayanan jasa pada bengkel " $X$ " berdasarkan hasil matrix Importance - Performance Analysis (studi kasus di Bengkel AHASS PD. Sumber Motor Karawang', Institut Teknologi Nasional (Itenas), Bandung

Oktafiani, Z, Isnarosi, D, Ratih, N, Hardiyanti (2018) 'Pengukuran kepuasan konsumen outlet Notosuman Bakery Ngawi Jawa Timur dengan metode Importance Performance Analysis (IPA)'.

Patimah S, Priyono, B, S, Rasyid, W. (2016) 'analisis tingkat kepuasan konsumen terhadap pelayanan usaha benih padi Cigeulis di Balai Induk Padi dan Palawija di Kabupaten Kepahiang Provinsi Bengkulu', DeReMa Jurnal Manajemen, Vol. 15, No. 2, hal 203 -212.

Wijaya R., Lokajaya N, dan Khoiroh S M. (2018) 'Analisis Kepuasan pelanggan dengan metode Servqual dan peningkatan performa pelayanan dengan Importance Performance Analysis (IPA) Di CV. Erdy Service Surabaya', Jurnal Tugas Akhir, Universitas 17 Agustus 1945, Surabaya.

Wijaya, T. (2011) Manajemen kualitas jasa. PT. Indeks. Jakarta. 
KUALITAS PELAYANAN APLIKASI (Akbar G., dkk.)

Winanda A R, dan Sriyanto (2015) 'Analisis kualitas pelayanan restoran cepat saji dengan metode Servqual (Service Quality) Dan IPA (Importance Performance Analysis) (studi kasus Restoran Olive Fried Chiken)', Universitas Diponegoro, Semarang.

Yulianti. A. L. (2016) 'Pengaruh kualitas pelayanan terhadap kepuasan pelanggan pada JNE cabang Bandung', DeReMa Jurnal Manajemen, Vol. 11, No. 2, hal 270-271

\section{Ucapan Terima Kasih}

Ucapan terima kasih kami berikan kepada LPPM Universitas Sultan Ageng Tirtayasa atas kepercayaannya kepada kami untuk memberikan Hibah Internal melalui program penelitian dan kami ucapkan terima kasih kepada Aplikasi DANA yang bersedia untuk mendata responden pengguna dan dipublikasikan lebih lanjut. 